
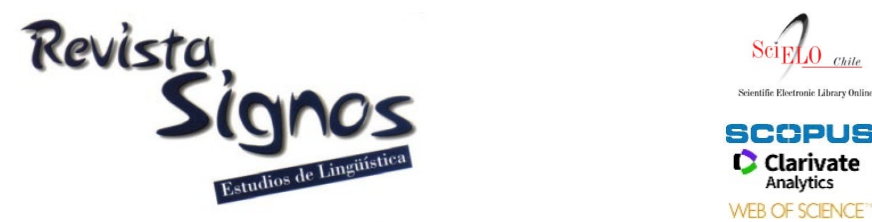

\title{
Epistemic context analysis
}

\author{
Análisis del contexto epistémico
}

\author{
Teun A. van Dijk \\ Centre of Discourse STUDies \\ SPAIN \\ vandijk@discourses.org
}

Recibido: 28-VI-2021 / Aceptado: $01-\mathrm{X}-2021$
DOI: $10.4067 /$ S0718-09342021000300758

\begin{abstract}
Within a general theory of communicative contexts and their influence on the structures, production and comprehension of discourse, this article focuses on the crucial, but often ignored, role of the knowledge of speakers about the knowledge of the recipients, earlier studied as 'common ground'. For communicative contexts to influence the structures of discourse, it is assumed that participants must have a mental model of that situation, including this specific knowledge controlling all epistemic aspects of discourse. Such knowledge must be inferred from previous (parts of) discourse, prior discourse and communication or an ongoing analysis of the communicative situation. A detailed analysis of a speech of former Prime Minister of the UK, David Cameron, on refugees shows that the general epistemic conditions of appropriate assertions in such speeches require a much more sophisticated theoretical and analytical approach than in classical pragmatics.
\end{abstract}

Key Words: Discourse studies, context models, knowledge, common ground, David Cameron, parliamentary discourse.

\section{Resumen}

Dentro de una teoría general de contextos comunicativos y su influencia en las estructuras producción y comprensión del discurso, este artículo se centra en el papel crucial, pero a menudo ignorado, del conocimiento de los hablantes sobre el conocimiento de los receptores, que solía estudiarse como 'terreno común'. Para que los contextos comunicativos influyan en las estructuras del discurso, se supone que los participantes deben tener un modelo mental de esa situación, incluyendo este conocimiento específico que controla todos los aspectos epistémicos del discurso. Tal conocimiento debe inferirse de (partes del) discurso existente, del discurso y comunicación previa o del análisis de la situación comunicativa en curso. Un análisis detallado de un discurso del ex primer ministro del Reino Unido, David Cameron, sobre los refugiados muestra que las condiciones epistémicas generales de las afirmaciones apropiadas en tales discursos 
requieren un enfoque teórico y analítico mucho más sofisticado que en la pragmática clásica.

Palabras Clave: Estudios del discurso, modelos de contexto, conocimiento, terreno común, David Cameron, discurso parlamentario.

\section{INTRODUCTION}

In his many studies of professional discourse studies, Giovanni Parodi not only shows he is an excellent discourse analyst, but also that he is aware of cognitive processes of text production and comprehension, as well as of the contextual nature of genres and the role of knowledge in professional discourse (among many other publications, see, e.g. Parodi, 2003, 2005, 2010, 2014).

It is within this perspective that this paper examines the fundamental role of knowledge as crucial, but sometimes ignored, part of the communicative context that defines the pragmatic appropriateness of text or talk. We do so within the larger framework of a theory of the communicative context, represented as context models, that control the production and comprehension of discourse.

From the outset, this relevance may be illustrated by a well-known rule of everyday conversation, namely that in general we should avoid telling people what we know they know already, typically countered by such protests as 'I know' or 'I know that' (Vatanen, 2018). And the converse also holds: We are not supposed to ask people what we know they don't know (Fiengo, 2007). Of course, for both rules there are specific exceptions, for instance in didactic contexts or political debate or everyday conversations between spouses or parents and children.

After a first general discussion of communicative contexts and their cognitive representation in terms of context models, we examine just one dimension of these models, namely the special device calculating in each situation and each moment of text or talk, what the participants know, and know about each other's knowledge, and how this aspect of the communicative situation influences the structures and the pragmatic functions and appropriateness of the discourse.

\section{Contexts}

As is the case in many disciplines, also linguistics and discourse studies examine phenomena in relation to some kind of 'context', informally defined as some kind of social, political or cultural environment that exerts influence of the phenomena studied. Thus, sociolinguistics may study phonological, lexical or syntactic variation as a function of gender, age or social class of the speakers (Bayley, Cameron \& Lucas, 2013). A pragmatic study of politeness phenomena in conversation typically examines the social relations, e.g., of power, hierarchy, familiarity or respect, among participants (Brown \& 
Levinson, 1987; Leech, 2014). And critical discourse studies may specifically focus on social or political domination, as abuse of power, or resistance enacted by discourse (van Dijk, 2008b). A sociological or political analysis of language use or discourse may examine contexts of racism, sexism, resistance or legitimation as part of the communicative or sociopolitical situation or as part of an organization, a political party, a government or a social movement or even larger social structures. Finally, linguistic anthropology as well as sociolinguistics may be interested in the cultural contexts of language use, discourse and interaction (Duranti \& Goodwin, 1992). In sum, there are many kinds of context, each studied in different (sub) disciplines of linguistics, discourse studies or various social sciences.

Metaphorically, we could represent such contexts as closer and more distant concentric circles of a social environment, depending on their influence on discourse. Thus, quite indirectly, everyday conversations, classroom interaction or news reports may be influenced by capitalism, democracy, governments, economic relations and much more, but these influences may be vague and indirect, and not always provide insight in the structures and functions of text or talk. More specific than these sociopolitical contexts, we may examine the social identities, roles and relations of the participants of conversation or communication, and some of these may influence aspects of discourse quite directly, as would be the case for the kind of speech acts engaged in (such as requests or commands), the use of pronouns, or specific politeness formula. In this paper we limit our analysis to the latter kind of the communicative context, that is, properties of the communicative situation that have systematic influence on the structures of discourse (for detail, see van Dijk, 2008a, 2009).

\section{Mental models}

The crucial theoretical question, largely ignored in for instance sociolinguistics or pragmatics, is how the properties of the communicative context are able to influence discourse in the first place. Thus, social properties such as the identity, roles and relations of participants in interaction and communication are typically described and analyzed in terms of social structures. How do such social structures influence the very different structures of language, language use or discourse?

To answer that fundamental empirical question of causation or conditioning between different phenomena, we need a cognitive interface. From a general constructivist perspective, also prevalent in cognitive psychology, we assume that language users as social actors interpret, understand, store and recall social structures in terms of some kind of mental representations, construed by applying socially shared knowledge. These mental representations may in turn influence the mental representations and processes involved in the production and comprehension of discourse. It is through such an interface that we are able to explain how the properties of the communicative situation may influence language use and discourse. 
Since the early 1980s, cognitive psychology introduced a useful theoretical notion that may serve as this kind of cognitive interface between text and context: mental models (Johnson-Laird, 1983; van Dijk \& Kintsch, 1983). Mental models are representation of specific situations and personal experiences, stored in autobiographical episodic memory. They are the mental basis of personal stories and in general underly all discourse about specific events, actions or situations, as is also the case for news reports in the press. Mental models show the usual parameters of events, such as Time, Place, Participants with different identities, roles and relations, as well as the events or actions in which they participate, possibly with personal opinions or emotions about the current event or situation. Telling a story, thus, consist in activating and expressing (aspects of such) mental models (Zwaan, Magliano \& Graesser, 1995). Conversely, when reading a story, we construe a metal model of the situation, and it is this mental model rather than the original story that influences our memory of the story, replying to questions or solving a problem. Extensive theoretical and experimental studies of the last 40 years have shown how fundamental these mental models are for the production and comprehension of discourse, if only to make sure that such discourse is globally and locally coherent (Graesser, Gernsbacher \& Goldman, 2003).

\subsection{Context models}

The cognitive psychology of discourse processing has widely accepted the notion of mental model to account for many aspects of production, comprehension and memory of discourse. These models account especially for semantics aspects, such as coherence, inferences and reference. However, neglected has been the important 'pragmatics' of discourse, defined in terms of 'appropriateness' of discourse in its communicative context (Verschueren, Östman, \& Blommaert, 1995). Language users not only construe mental models of the situation a discourse is 'about', but also of the communicative situation 'in which' they are participating. We call these models 'context models' (for detail, see van Dijk, 2008a, 2008b).

Such models account for the fact that there is no direct relationship between properties of the communicative situation, such as Time, Place, Participants (and their Identities, Roles and Relations), and the ongoing communicative action, on the one hand, and the structures of discourse, on the other hand. Context models provide the necessary cognitive interface between this communicative situation and discourse (for detail, see van Dijk, 2008a, 2009).

Many aspects of discourse depend on the properties of the communicative situation, as is the case for speech acts, politeness and indexical expressions, properties language users need to have access to immediately, in fractions of seconds, to be able to produce or understand the discourse structures that depend on them. This means that during discourse processing context models monitor online, probably in Short Term Memory, 
many aspects of discourse. Hence, context models must be rather simple, consisting of a standard schema of basic categories of the communicative situation.

Parts of contexts models are probably already in place before the onset of talk or text: In many situations we already know in advance the basic communicative properties of a conversation with a friend, a lesson in the classroom, a visit in a shop or to the doctor, or reading the newspaper.

During discourse the context models will then be completed with new or changed properties of the communicative situation, such as the relations between the participants, and especially the knowledge of the participants.

\section{The knowledge device}

Many approaches to the properties of the communicative situation have been studied in pragmatics and sociolinguistics. This is not the case for the knowledge of the participants, despite the fact that such knowledge is crucial for many aspects of discourse, such as coreference, presuppositions, topic-focus relations, and much more (among many studies, see Achim, Achim, \& Fossard, 2017; Clark, 1996; Krauss \& Fussell, 2014/1990; Lee, 2001). Hence, relevant knowledge must be present or at least indexed in context models, so that language users in many ways can adapt their discourse to the knowledge of the recipients.

Context models are 'dynamic' because participants ongoingly adapt them to the changing communicative situation. Identity and relations between participants may change during a conversation, and especially their knowledge is permanently updated, if only because recipients adapt their knowledge to what has just been said by the speaker. Speakers in turn also adapt their knowledge to this changed knowledge of the recipients. Hence the general epistemic rule that speakers in principle should not repeat what they have just said, unless as a form of strategic emphasis.

The theoretical, empirical and practical problem is: How do language users know about the knowledge of the recipients, knowledge that is less directly accessible than other aspects of the communicative situation, such as Time, Place, Participants etc? Hence, we assume that language users must infer such knowledge from other information available in text, context or memory:

(i) Co-text: Knowledge inferred from the semantic representation of previous parts of the discourse or from the situation model construed so far for the ongoing discourse.

(ii) Communicative context: Knowledge inferred from the ongoing moment of the communicative situation, as represented in the context model, such as Time, Place, Participants (and current Identity, Role or relations) and the ongoing communicative action. 
(iii) Previous discourse and interaction and the knowledge derived from such discourse where relevant for the ongoing discourse. Since such knowledge after some delay many no longer be complete, detailed or precise, language users may engage in reminding and checking upon the memory of recipients about what was said and communicated at the previous occasion.

(iv) Personal knowledge about the recipients, e.g. among friends and family members, usually also implies knowledge about the knowledge of the recipients (Planalp \& Garvin-Doxas, 1994).

(v) Relevant sociocultural knowledge shared in the relevant epistemic community, as well as accessible inferences from such knowledge. Whereas the knowledge of (i) to (iii) is mostly personal and unique to the participants, sociocultural knowledge is socially shared and also needed to construe the situation models for ongoing discourse.

For language users to be able to access this knowledge and to make these inferences, they need to engage in efficient strategies so that for each fragment of discourse the relevant knowledge is available in order to produce and understand current presuppositions and other structures of discourse. Thus, although speakers may assume that in general recipients have access to the information mentioned in (i) to (iv), they also must count with the possibility that recipients have forgotten or did not pay attention to what was just said, or what was said on previous occasions. In this case, various kinds of more or less explicit reminders are in order to check and update the knowledge of the recipients to that they understand the current clause, sentence or paragraph of the discourse.

Hence, our theoretical proposal complements earlier studies on common ground (see references above) on shared or mutual knowledge (see, e.g., Mercer, 1987; Kreckel, 1981), as well as contemporary studies on the epistemics of conversation (among a vast bibliography, see Heritage, 2012; Raymond, 2018; Seuren, Huiskes \& Koole, 2018), or beliefs about prior knowledge in professional discourse (Tillema \& Orland-Barak, 2006).

\section{Example}

To illustrate the role of knowledge as part of the context model of the language users, let us briefly analyze an example of public discourse, namely a speech Prime Minister (PM) David Cameron pronounced in the House of Commons of the UK on Monday 7 September, 2015, during the 'refugee crisis' of 2015-2016. This is how this speech begins:

The Prime Minister (Mr David Cameron): Before I make a statement on counterterrorism, Mr Speaker, let me update the House on what we are doing to help address the migration crisis in Europe and, in particular, to help the thousands of refugees who are fleeing Syria. 
This issue is clearly the biggest challenge facing countries across Europe today. More than 300,000 people have crossed the Mediterranean to Europe so far this year. These people came from different countries under different circumstances. Some are economic migrants in search of a better life in Europe; many are refugees fleeing conflict. It is vital to distinguish between the two.

Let us begin by summarizing the properties of this fragment that depend on the communicative situation, and hence are usually called indexical expressions:

Table 1. Contextual Análisis.

\begin{tabular}{|l|l|}
\hline Parameters of the Communicative Situation & Indexical expressions \\
\hline Current time & $3: 30$ PM (added in Hansard Transcript) \\
& $\begin{array}{l}\text { Before, today, recent weeks, since January } \\
\text { Tenses: are fleeing, came, etc. }\end{array}$ \\
\hline Current Location & $\begin{array}{l}\text { UK House of Commons (implicit) } \\
\text { The House }\end{array}$ \\
\hline Personal Identity: David Cameron & Made explicit by Hansard transcript \\
\hline Political/Professional Identity: Prime Minister & Made explicit by Hansard transcript \\
\hline Role: Current speaker & First person pronouns: I, me \\
\hline Role: Current addressee & Mr. Speaker \\
\hline Role: Current indirect addressee & The House \\
\hline Current action & Speech in parliament (implicit) \\
\hline Next (part of current) action & a statement \\
\hline Party/Government/Group/Institution/Country of speaker & we \\
\hline
\end{tabular}

One of the interesting indexical expressions used in the first sentence is the personal pronoun 'we', usually referring to a collective of which the speaker is a member or representative. In this case, such a reference is vague, because Cameron may refer to his government, to parliament (including the addressees) or the UK. By pragmatic rule of positive self-presentation, it may however be interpreted as a positive act of his government of the UK.

Besides the many deictic expressions referring to dimensions of the communicative context, including implicit ones expressed by the Hansard transcript, or implicitly derivable from the knowledge of the participants (such as current time, place, current communicative act, and the identity of the participants), David Cameron also signals what knowledge the recipients have. First of all, by using the verb 'to update', he implies that the information he in going to convey is probably new for many or most of the MPs. This communicative verb is followed by a summary of what he is going to say right now, so that the MPs now know what he is going to talk about, although Cameron may also assume the MPs already know after this session of parliament, and its topic, were announced. Hence, we here see a first complication in the assignment of knowledge as represented by the participants: On the one hand Cameron knows that the MPs don't know what he is going to say, but on the other hand, he knows that they 
know what the overall topic of this first part his speech will be - preceding the part on counter-terrorism, also indexed by a summarizing theme in the same sentence.

The definite expression 'the House' not only indexes the current location as well as the current Institution that are part of the ongoing communicative situation, but the definite expression at the same time indexes that the recipients know both the place and the institution, also inferable from their own identity as (present) MPs.

Routine is the expression 'the migration crisis' whose definite article indexes that this crisis is known to the MPs, and at the same time represents the events talked about - hence part of the (semantic) situation model interpreting the current speech. Interesting though is the very choice of this indexical expression, because at the same time, there have been various types of public discourse, no doubt known to Cameron, protesting against such a negative denomination of the political situation, often also referred to as a 'crisis of Europe' or a 'crisis of democracy'. Moreover, though speaking about refugees, Cameron prefers to speak more generally about a 'migration' crisis, and for his recipients in the House, or the general public, such a lexical choice may be heard as a political decision, of the leader of the Conservative Party, to treat refugees as migrants. We see that lexical choice may signal another aspect of the communicative situation, namely the political attitude of the speaker. Cameron's knowledge about the knowledge of the MPs (about the 'migration crisis') is inferred from his knowledge about the socially shared knowledge of the political situation in Europe, and the general debate about it. Indeed, more generally, speakers presuppose the knowledge of recipients about current affairs, and in parliament especially about its political aspects, typical part of the sociopolitical Common Ground.

The same holds for the next definite expression 'the thousands of refugees', specifying the more general topic of the 'migration crisis', because Cameron knows that the MPs all know about these refugees and where they are coming from.

More complicating is Cameron's reference 'to what (we) are doing to help' as part of the topic (actually a complete semantic macroproposition). Since that part depends on the communication verb 'to update', this part of the sentence is signalled as new knowledge for the MPs, but again, at least part of this knowledge is probably public and hence known to the MPs - if the UK has indeed been helping the refugees. Also this example suggests that an epistemic analysis of the text may require a detailed epistemic analysis of the communicative context, by inquiring what speakers know exactly about the knowledge of the hearers. And such an epistemic analysis of the communicative situation probably needs to introduce 'degrees of knowledge', such as information that is totally new to the recipients, information that is partly or vaguely known from current public discourse and debate, or what may be inferred from the identity and role of the speaker, as Prime Minister, as Leader or the Conservative Party, and finally knowledge 
the speaker knows is shared by the recipients, as is signalled here by the definite expressions 'the migration crisis and the thousands of refugees'.

The expression at the beginning of the next paragraph, 'this issue', is interesting for various reasons. First it is a co-referring expression although no issue has been mentioned in these words, so that the expression refers to the political situation or the crisis, as described by the previous paragraph. Obviously, such an interpretation not only requires a discourse analytical framework, but more specifically more global units such as topics summarizing fragments of discourse. In terms of the knowledge of the recipients, discussed here, we now see that such knowledge may be derived from previous parts of a discourse, and more specifically by the macroproposition expressed by the previous paragraph. Indeed, it would have been semantically strange if Cameron had co-referred to the situation described by previous information by an expression such as 'this adventure', or 'this party'. To avoid common mistakes about coherence and co-reference, recall that the expression 'this issue' does not refer to the previous paragraph, nor even to the information of the previous paragraph, but to a specific social or political situation in the world, such as a crisis, although 'issue' may also refer to a 'topic' of debate about such a political situation. In other words, the co-reference requires a (semantic) mental model, shared by the participants, with information allowing such co-referential expressions.

The next definite expression 'the biggest challenge facing countries across Europe today' has similar subtle and complex epistemic implications. The definite expression signals that the speaker knows that the MPs know about this challenge, and the adverb 'clearly' suggest that this challenge is important and hence public knowledge. However, the semantic structure of the word 'challenge', implies a 'difficulty' and hence may imply an appraisal, as would be the word 'problem', and hence an opinion of the speaker about the current political situation. Under this interpretation, there is no shared knowledge, but contextually new opinion: the current evaluation by Cameron of the current situation.

The next sentence, 'More than 300,000 people have crossed the Mediterranean to Europe so far this year', is epistemically interesting, not only because it is a straight statement of fact, though numerically vague. But Cameron engages here in an assertion of information he probably knows all or most MPs know about, and hence strictly speaking flouting an epistemic condition of assertions. Since such a statement of a known fact is perfectly appropriate in the current debate, we must conclude that in specific situations, for instance at the beginning of a discussion or debate, as well as in didactic contexts, speakers may make statements about facts known to the recipients, if only as a summary or introduction for new information in the debate. This is also the case for the next sentence 'These people came...' also referring to known facts, and hence represented in the mental model of the current crisis in the minds of the recipients. 
The next two sentences, 'Some are economic migrants in search of a better life in Europe; many are refugees fleeing conflict. It is vital to distinguish between the two' are no longer about facts but express an opinion, namely how the refugees are denominated as 'migrants', and what is attributed to them, being 'economic' and 'in search of a better life', a description which implies they are no refugees, an implication explicitly confirmed in the next sentence. That Cameron is expressing an opinion is signalled by the evaluative expression 'it is vital'. Thus, part of the expression 'many are refugees fleeing conflict' is no doubt true, and hence a statement of fact, but the quantifier ('many') may be part of the opinion when the truth is that all these migrants are refugees fleeing conflict. Here epistemic and doxastic analysis overlap and conflict. No doubt the opinion of Cameron and his government about migrants and refugees are known to the MPs, and in that sense the opinion is nothing new. Also, the part of the formulation of the opinion implies knowledge about facts (refugees fleeing conflicts) shared by all MPs, but another part (the distinction between migrants and refugees) may not be, and hence no longer satisfies the general criteria of accepted knowledge but expresses a personal or political opinion. The rest of Cameron's speech, as well as the debate similarly expresses knowledge of new facts with known or new opinions of Cameron and the MPs.

For the discussion of this paper, what is relevant here is the complexity of what counts as speaker knowledge about the knowledge of the recipients. We have seen that the discourse may signal some knowledge as generally known and shared, whereas other knowledge must be politically inferred, e.g., about the policies of Cameron, the political government (about helping refugees), and again other knowledge associated with personal or political opinions of the speaker.

Thus some knowledge is presupposed and generic, socially shared, such as the knowledge about counter-terrorism, refugees, Syria, the Mediterranean or Europe. Other knowledge may have evaluative aspects, as when describing the 'issue' or the situation as a 'crisis', whereas some denominations, such as 'economic migrants' are descriptions or facts for the speaker, but a statement of opinion for many MPs and many people in the UK. Even if Cameron no doubt knows that all the MPs know his opinion about refugees and migrants, such information cannot be presupposed, as is the case for shared knowledge, but need to be expressed as a statement of an opinion.

\section{CONCLUSION}

In sum, if traditional speech analysis (Searle, 1969) defines a speech acts of assertion in terms of the knowledge of the Speaker about the lack of knowledge of the Hearer, we see that a brief context analysis of the knowledge of the participants of a parliamentary debate requires a much more detailed and sophisticated analysis. Thus, for Cameron to speak appropriately in the current debate, and for MPs to understand 
and interpret what he says, we need a very subtle analysis of the epistemic device of their context models.

That such a device is necessary as part of the context model has been shown in order to account for the pragmatic aspects of discourse, beyond the usual analysis of indexical expressions, politeness or implicatures. Not only have we found how complex knowledge is involved in discourse production and comprehension, but also that it is equally complex to distinguish and combine an epistemic and doxastic analysis of this kind of political discourse.

We have not even examined in how far the doxastic parts of Cameron's speech express not only a personal opinion or a political attitude about refugees, but where this speech from the starts also needs an 'ideological analysis' of conservative, or even racist discourse. Indeed, we may have to add not only an epistemic device to context models, but even an ideological component accounting for a crucial property of the participants, at least in many contexts, and always in political debates in parliaments.

The question however is whether in that case we still are within the scope of a pragmatic analysis accounting for the 'appropriateness' of discourse. Thus, if Cameron, as conservative Prime Minister would suddenly agree with the 'progressive' opinion that all migrants are 'forced' migrants and hence refugees, such would be surprising and unexpected, but we could hardly say in that case that a speech making such an assertion is inappropriate. On the other hand, it might be found 'inappropriate' or 'not done' by other conservatives, but in that case rather as an 'unacceptable' opinion, but not as an 'inappropriate' speech. We see that we are here at the border of the scope of pragmatic epistemic analysis, on the one hand, and ideological, political analysis of discourse on the other hand.

\section{REFERENCES}

Achim, A. M., Achim, A. \& Fossard, M. (2017). Knowledge likely held by others affects speakers' choices of referential expressions at different stages of discourse. Language Cognition and Neuroscience, 32(1), 21-36.

Bayley, R., Cameron, R. \& Lucas, C. (2013). The Oxford handbook of sociolinguistics. Oxford New York: Oxford University Press.

Brown, P. \& Levinson, S. C. (1987). Politeness: Some universals in language usage. New York, NY: Cambridge University Press.

Clark, H. H. (1996). Using language. Cambridge, England: Cambridge University Press.

Duranti, A. \& Goodwin, C. (Eds.) (1992). Rethinking context: Language as an interactive phenomenon. Cambridge: Cambridge University Press. 
Fiengo, R. (2007). Asking questions. Using meaningful structures to imply ignorance. Oxford / New York: Oxford University Press.

Graesser, A. C., Gernsbacher, M. A. \& Goldman, S. R. (Eds.) (2003). Handbook of discourse processes. Mahwah, N.J.: Lawrence Erlbaum.

Heritage, J. (2012). Epistemics in action: Action formation and territories of knowledge. Research on Language and Social Interaction, 45(1), 1-29.

Johnson-Laird, P. N. (1983). Mental models. Cambridge: Cambridge University Press.

Krauss, R. M. \& Fussell, S. R. (2014/1990). Mutual knowledge and communicative effectiveness. In J. Galegher, R. E. Kraut \& C. Egido (Eds.), Intellectual teamwork (pp. 125-160). New York: Psychology Press.

Kreckel, M. (1981). Communicative acts and shared knowledge in natural discourse. London and New York: Academic Press.

Lee, B. P. H. (2001). Mutual knowledge, background knowledge and shared beliefs: Their roles in establishing common ground. Journal of Pragmatics, 33(1), 21-44.

Leech, G. N. (2014). The pragmatics of politeness. Oxford /New York: Oxford University Press.

Mercer, N. (Ed.) (1987). Common knowledge: The development of understanding in the classroom. London/New York: Methuen.

Parodi, G. (2003). Relaciones entre lectura y escritura: Una perspectiva cognitiva discursiva. Bases teóricas y antecedentes empírico. Valparaiso: Ediciones Universitarias.

Parodi, G. (2005). Comprensión de textos escritos. Buenos Aires: Eudeba.

Parodi, G. (Ed.) (2010). Academic and professional discourse genres in Spanish. Amsterdam Philadelphia: John Benjamins.

Parodi, G. (2014). Genre organization in specialized discourse: Disciplinary variation across university textbooks. Discourse Studies, 16(1), 65-87.

Planalp, S. \& Garvin-Doxas, K. (1994). Using mutual knowledge in conversation: Friends as experts on each other. In S. Duck (Ed.), Dynamics of relationships (pp. 1-26). Thousand Oaks, CA: Sage

Raymond, G. (2018). Which epistemics? Whose conversation analysis? Discourse Studies, 20(1), 57-89.

Searle, J. R. (1969). Speech acts: An essay in the philosophy of language. London: Cambridge U.P. 
Seuren, L., Huiskes, M. \& Koole, T. (2018). Resolving knowledge discrepancies in informing sequences. Language in Society, 47(3), 409-434.

Tillema, H. \& Orland-Barak, L. (2006). Constructing knowledge in professional conversations: The role of beliefs on knowledge and knowing. Learning and Instruction, 16(6), 592-608.

Van Dijk, T. A. (2008a). Discourse and context. A sociocognitive approach. Cambridge, UK New York: Cambridge University Press.

Van Dijk, T. A. (2008b). Discourse and power. Basingstoke/ England New/ York: Palgrave Macmillan.

Van Dijk, T. A. (2009). Society and discourse. How social contexts influence text and talk. Cambridge New York: Cambridge University Press.

Van Dijk, T. A. \& Kintsch, W. (1983). Strategies of discourse comprehension. New York/Toronto: Academic Press.

Vatanen, A. (2018). Resisting an action in conversation by pointing out epistemic incongruence: Mä tiedän 'I know' responses in Finnish. Journal of Pragmatics, 123, 192-208.

Verschueren, J., Östman, J. O. \& Blommaert, J. (Eds.). (1995). Handbook of pragmatics. Amsterdam Philadelphia: John Benjamins.

Zwaan, R. A., Magliano, J. P. \& Graesser, A. C. (1995). Dimensions of situation-model construction in narrative comprehension. Journal of Experimental Psychology: Learning, Memory, and Cognition, 21, 386-397. 